\title{
“波叶金桂”对干旱和高温胁迫的生理生态响应
}

\author{
汪俊宇王小东马元丹傅卢成 周欢欢王彬 张汝民高 岩*
}

浙江农林大学亚热带森林培育国家重点实验室, 浙江临安 311300

摘 要 为了探讨植物对干旱、高温及协同胁迫的响应, 该研究以木犀(Osmanthus fragrans) “波叶金桂'为材料, 采用盆栽质 量控水法模拟干旱胁迫 (对照、轻度、中度和重度)和高温胁迫, 利用动态顶空气体循环吸附法和热脱附-气相色谱-质谱 (TDS-GC-MS)联用技术对其挥发性有机化合物(VOCs)进行测定; 同时测定其非结构性碳(NSC)含量及次生代谢酶活性。结果 表明: 干旱胁迫对“波叶金桂”叶片NSC组分含量影响不显著; 可溶性糖和淀粉含量在高温胁迫下显著降低, 在协同胁迫后持 续性下降，重度协同胁迫下，葡萄糖、果糖、蔗糖和淀粉分别比对照降低 $47.7 \% 、 46.4 \% 、 34.4 \%$ 和 $38.2 \%$ 。干旱胁迫和协同胁 迫下3-羊基-3-甲基戊二酸单酰辅酶A还原酶(HMGR)、1-脱氧木酮糖-5-磷酸还原酶(DXR)活性表现出先上升后下降，而脂氧合 酶(LOX)活性表现出持续性上升趋势; 高温胁迫后, HMGR、DXR和LOX活性显著高于对照。干旱胁迫下萜烯类VOCs释放量 表现出先上升后下降趋势, 中度干旱胁迫和高温胁迫下分别比对照高 $37.9 \%$ 和 $32.3 \%$; 协同胁迫下萜烯类释放量逐渐降低, 干 旱、高温和协同胁迫诱导醛类释放量明显增加。上述结果表明: 干旱胁迫条件下, “波叶金桂”通过NSC进行自我渗透调节，同 时合成大量萜烯类化合物来提高抗旱性; “波叶金桂”调控萜烯类化合物合成以及绿叶挥发物(GLVs)的释放抵御高温胁迫; 协 同胁迫下萜烯类化合物的合成途径受阻, “波叶金桂”提高GLVs合成与释放量抵御协同胁迫; 中度和重度协同胁迫导致“波叶 金桂’细胞膜严重受损，自我调节能力降低。

关键词 木犀; 干旱高温胁迫; 非结构性碳; 挥发性有机化合物; 次生代谢酶

汪俊宇, 王小东, 马元丹, 傅卢成, 周欢欢, 王彬, 张汝民, 高岩 (2018). “波叶金桂”对干旱和高温胁迫的生理生态响应. 植物生态学报, 42, 681-691. DOI: $10.17521 /$ cjpe.2018.0017

\section{Physiological and ecological responses to drought and heat stresses in Osmanthus fragrans 'Boyejingui'}

WANG Jun-Yu, WANG Xiao-Dong, MA Yuan-Dan, FU Lu-Cheng, ZHOU Huan-Huan, WANG Bin, ZHANG Ru-Min, and GAO Yan*

The State Key Laboratory of Subtropical Silviculture, Zhejiang Agriculture and Forestry University, Lin'an, Zhejiang 311300, China

\begin{abstract}
Aims Drought and heat stresses are two critical environmental factors affecting the growth and development of plants; climate change has exacerbated the occurrence of these conditions in many parts of the world. To elucidate the mechanisms of responses to drought and heat stresses in Osmanthus fragrans, we studied changes in nonstructural carbohydrate (NSC) and volatile organic compounds (VOCs) emissions using 3-year-old seedlings (cultivar 'Boyejingui') under conditions of low drought (LD), moderate drought (MD) and severe drought (SD), interactively with heat treatments $\left(40^{\circ} \mathrm{C}\right.$ in daytime $(12 \mathrm{~h})$ and $30^{\circ} \mathrm{C}$ at night $\left.(12 \mathrm{~h})\right)$.

Methods The VOCs emissions were measured using the dynamic headspace air-circulation method, and the composition and content of VOCs were analyzed using the thermal desorption system/gas chromatography/mass spectrometer technique (TDS-GC-MS). We determined the content of NSC and activities of lipoxygenase (LOX), 3-hydroxy-3-methylglutaryl-CoA reductase (HMGR) and 1-deoxy-D-xylulose 5-phosphate reductoisomerase (DXR) in seedlings under different drought and heat treatments.

Important findings The content of NSC in leaves was not significantly affected by drought stress. The contents of soluble sugar and starch were significantly reduced by heat stress as well as combination of drought and heat stresses. The combination of severe drought and heat treatment significantly reduced the contents of glucose, fructose, sucrose and starch by $47.7 \%, 46.4 \%, 34.4 \%$ and $38.2 \%(p<0.05)$, respectively. There were differences
\end{abstract}

收稿日期Received: 2018-01-14 接受日期Accepted: 2018-05-12

基金项目: 国家自然科学基金(31470704和31270756)。Supported by the National Natural Science Foundation of China (31470704 and 31270756 ).

* 通信作者Corresponding author (gaoyan1960@sohu.com) 
among the activities of HMGR, DXR and LOX in response to drought and heat stresses. Under drought and combined stresses, the activities of HMGR and DXR increased first and then decreased, and the LOX activity increased. The activities of HMGR, DXR and LOX were significantly higher under heat stress than in controls. The release of terpenes increased first and then decreased with the level of drought treatments. MD and SD stress stimulated the release of terpenes by $37.9 \%$ and $32.3 \%(p<0.05)$, respectively, but the combined stresses induced a reduction in the release of terpenes. The release of aldehydes increased significantly in response to drought, heat treatment, and their combination. The results indicated that 'Boyejingui' seedlings can enhance resistance to drought stress by adjusting contents of non-structural carbohydrate and releasing terpene compounds. They also adjusted the biosynthesis of terpene compounds and GLVs emission to resist against heat stress. However, the biosynthesis pathway of terpene compounds was blocked in the occurrence of both drought and heat stresses, when the enhanced release of GLVs facilitated the resistance. Under heat stress, moderate and severe drought caused severe damage to cell membranes, thus reducing the self-regulatory capacity.

Key words Osmanthus fragrans; drought and heat stress; non-structural carbohydrate; volatile organic compounds; secondary metabolic enzymes

Wang JY, Wang XD, Ma YD, Fu LC, Zhou HH, Wang B, Zhang RM, Gao Y (2018). Physiological and ecological responses to drought and heat stresses in Osmanthus fragrans 'Boyejingui'. Chinese Journal of Plant Ecology, 42, 681-691. DOI: 10.17521/cjpe.2018.0017

非结构性碳水化合物(NSC)作为植物体内的可 溶性碳库, 不仅为植物生长发育提供碳源与能源, 还能调控植物生理活动(Hoch et al., 2003); 同时, 植物体内 $\mathrm{NSC}$ 的积累是一种重要的渗透调节保护机 制(Lin et al., 2014; Murcia et al., 2015)。干旱胁迫导 致欧洲云杉(Picea abies)树根NSC含量减少, 在地 上和地下组织之间的碳分配、使用和运输方面有显 著差异(Hartmann et al., 2013), 随干旱胁迫时间的 延长, 刺槐(Robinia pseudoacacia) 叶片NSC含量降 低(Zhang et al., 2015)。Marias等(2017)研究发现热处 理能够诱导西黄松(Pinus ponderosa) 和花旗松(Pseudotsuga menziesii)淀粉含量减少, 果糖和葡萄糖含 量增加, 总 NSC和蔗糖含量并没有受到影响。随着 高温干旱协同胁迫加剧, 新疆梨(Pyrus sinkiangensis) 可溶性糖含量呈上升趋势, 淀粉含量逐渐降低 (穆蓁蓁, 2015)。受到环境胁迫时, 植物初级代谢发 生紊乱, 可溶性糖的积累受到严重影响。蔗糖裂解 为果糖和葡萄糖, 不仅作为代谢物质和能量来源, 还充当信号分子, 通过信号转导途径识别, 协调合 成代谢和分解代谢过程, 促进植物生长发育( Li \& Sheen, 2016)。

植物释放的挥发性有机物(VOCs) 能够维持类 囊体膜的完整性, 起到抗氧化作用(Velikova et al., 2011; Arab et al., 2016); 在抵御逆境胁迫方面发挥 重要的信号作用(Loreto \& Schnitzler, 2010; Bourtsoukidis et al., 2014)。Arab等(2016)研究海柊(Phoenix dactylifera)发现, 高温诱导使异戊二烯排放大幅增 加; 同时, 在干旱胁迫下脂肪酸增加。Staudt等(2017)
发现温度升高能够提高Quercus ilex和Quercus pubescens类异戊二烯的排放量; 干旱胁迫提高单萜释 放量，同时减少类异戊二烯的排放。高温胁迫后花 旗松倍半萜、水杨酸甲酯、芳樟醇比单萜排放释放 量增加更快(Joó et al., 2011)。刘芳等(2013)研究发现, 迷迭香(Rosmarinus officinalis) VOCs中萜类和醛类 化合物受到干旱胁迫诱导表现出显著增加。VOCs 释放有助于诱导植物非生物应激性抵抗, 增强植物 抵御非生物胁迫能力(周帅等, 2012)。

植物VOCs释放受到相关酶的调控。甲羟成酸 和甘油醛磷酸/丙酮酸两条途径是合成萜烯类化合 物的主要途径(Dudareva et al., 2013), 3-羟基-3-甲基 戊二酸单酰辅酶 $\mathrm{A}$ 还原酶 (3-hydroxy-3-methylglutaryl CoA reductase, HMGR)和1-脱氧木酮糖-5磷酸还原酶(1-deoxy-D-xylulose 5-phosphate reductoisomerase, DXR)分别是两个途径的关键限速酶 (Ramak et al., 2013), 直接调控萜烯类化合物的生 物合成(Moses et al., 2013)。植物释放绿叶挥发物 (GLVs) 是由环境胁迫诱发的一种防御反应, 植物通 过调控其中关键酶——脂氧合酶 (lipoxygenase, LOX)——催化不饱和脂肪酸形成GLVs (Hassan et al., 2015)。因而HMGR、DXR和LOX活性的提高诱导 VOCs的形成是植物增强抗胁迫能力的重要前提。

木犀(Osmanthus fragrans)为木犀科常绿乔木或 灌木, 中国十大名花之一, 树形优美, 芳香袭人, 是重要的园林芳香植物。木犀品种资源丰富, “波叶 金桂, 作为金桂品种群中观赏价值很高的优异品种, 具有很高的研究价值。在全球气候变暖的大环境背

www.plant-ecology.com 
景下, 杭州夏季持续高温干旱, 导致大量植物受到 伤害, 成为制约当地农林业可持续发展的关键限制 因子(陈柯辰, 2013; Hijioka et al., 2014)。为了研究植 物非结构性碳、VOCs及相关酶代谢对干旱高温交 互作用的响应, 本研究以“波叶金桂”为对象, 通过 控制水分和温度模拟干旱高温胁迫对非结构性碳 含量、VOCs组分以及次生代谢酶活性的影响,揭示 “波叶金桂”在防御干旱高温胁迫反应中可溶性碳库 的变化和VOCs含量与次生代谢酶活性的生理响应 调节机制，以及“波叶金桂”在抵抗干旱、高温及协同 胁迫方面的应对对策; 同时为植物多样性保护、园 林植物的合理利用以及可持续发展提供参考。

\section{1 材料和方法}

\section{1 供试材料}

试验材料为三年生“波叶金桂” (浙江杭州画境 种业有限公司提供)。2016年4月选取长势良好的苗 木栽植于盛有培养土(泥炭:沙土:蛭石体积比 $1: 2: 1$, 干质量 $1.5 \mathrm{~kg}$ )的花盆中 (直径 $25 \mathrm{~cm}$, 高 $30 \mathrm{~cm}$ ), 苗高 $40 \mathrm{~cm}$ 左右, 每盆 1 株, 共计 40 盆。苗木培植于温室 (昼/夜 $30{ }^{\circ} \mathrm{C} / 25{ }^{\circ} \mathrm{C}$, 相对湿度 $40 \%$ )进行正常的栽培 管理。充分缓苗1个月，再实施控水胁迫。

\section{2 试验处理}

选取盆栽苗 40 盆, 随机分为 8 组, 其中 4 组用作 干旱处理, 剩余4组干旱处理后再进行高温处理。

干旱胁迫: 试验根据土壤含水量设置对照 $(\mathrm{CK}$, $75 \%$ 田间持水量 $(\mathrm{FC}))$ 、轻度干旱 $(\mathrm{LD}, 60 \% \mathrm{FC})$ 、中 度干旱( $\mathrm{MD}, 40 \% \mathrm{FC}$ )、重度干旱 $(\mathrm{SD}, 20 \% \mathrm{FC}) 4$ 个水 分梯度。采用称质量法控制土壤水分含量, 每天 18:00称质量并补充消耗的水分，维持土壤含水量。 每个处理 5 盆, 每盆作为 1 个独立重复实验, 每个梯 度土壤含水量达标后维持处理 3 天, 第 4 天 $10: 00$ 测 定各项指标。

高温胁迫: 将对照组和每个干旱梯度胁迫后的 苗木，放入人工气候箱(昼/夜 $40{ }^{\circ} \mathrm{C} / 28{ }^{\circ} \mathrm{C}, 12 \mathrm{~h} / 12 \mathrm{~h}$, 相对湿度 $40 \%$, 光照强度 $400 \mu \mathrm{mol} \cdot \mathrm{m}^{-2} \cdot \mathrm{s}^{-1}$ ) 进行高 温胁迫处理 2 天。将对照组进行高温胁迫作为高温 组, 其他作为协同组。每个处理 5 盆, 每盆作为 1 个 独立重复实验。

\section{3 试验方法}

可溶性糖含量测定: 称取 $0.5 \mathrm{~g}$ 植物叶片, 研磨 至匀浆, 加蒸馏水 $9 \mathrm{~mL}$, 沸水浴提取 $10 \mathrm{~min}$, 不断摚
拌。冷却, 离心 $\left(3000 \mathrm{r} \cdot \mathrm{min}^{-1}, 5 \mathrm{~min}\right)$ 后取上清液。 蔗糖、果糖和葡萄糖含量分别采用果糖和蔗糖试剂 盒(南京建成科技有限公司)、葡萄糖试剂盒(上海 荣盛生物药业有限公司)测定, 具体方法按说明书 操作。

淀粉含量测定: 将上述提取可溶性糖后的沉淀 用 $80 \%$ 乙醇冲洗 1 遍, 加蒸馏水 $3 \mathrm{~mL}$, 搅拌均匀, 沸 水浴 $15 \mathrm{~min}$ 。冷却后, 加入冷的高氯酸 $\left(9.2 \mathrm{mmol} \cdot \mathrm{L}^{-1}\right)$ $4 \mathrm{~mL}$, 搅拌提取 $20 \mathrm{~min}$, 蒸馏水定容至 $25 \mathrm{~mL}$, 混匀, 离心(3 $\left.000 \mathrm{r} \cdot \mathrm{min}^{-1}, 10 \mathrm{~min}\right)$ 。取上清液, 采用葱酮硫 酸法进行测定。

HMGR 和DXR酶液提取: 称取 $0.5 \mathrm{~g}$ 冰冻叶片, 加 $5 \mathrm{~mL}$ Tris-HCl缓冲液(50 $\mathrm{mmol} \cdot \mathrm{L}^{-1}, \mathrm{pH}$ 值7.5), 冰 浴条件下研磨至匀浆, $10000 \mathrm{r} \cdot \mathrm{min}^{-1}$ 离心 $30 \mathrm{~min}$ $\left(4{ }^{\circ} \mathrm{C}\right)$, 取上清液, 用于HMGR和DXR活性的测定 以及蛋白质含量测定。

HMGR 活性测定：测定方法参照 Toroser和 Huber (1998)的方法并略作修改。反应总体积为 $1 \mathrm{~mL}$ 。取 $980 \mu \mathrm{L}$ Tris-HCl缓冲液 $\left(150 \mathrm{mmol} \cdot \mathrm{L}^{-1}, \mathrm{pH}\right.$ 值7.5), 加入 $20 \mu \mathrm{L}$ 酶液。立即计时, 用紫外分光光 度计在 $340 \mathrm{~nm}$ 处检测还原型辅酶II (NADPH)的氧 化情况, 每隔 $10 \mathrm{~s}$ 检测一次, 连续测定 $5 \mathrm{~min}$, 测得 无底物 $\beta$-羊弪[基]- $\beta$-甲成二酸单酰辅酶A (HMG-CoA) 的情况下NADPH的氧化速率 $(a)$ 。反应体系同上, 取 $940 \mu \mathrm{L}$ 反应液, 加 $20 \mu \mathrm{L}$ 酶液, 再加 $40 \mu \mathrm{L}$ HMG$\mathrm{CoA}$ 液。操作步骤同上, 测得有HMG-CoA情况下 的NADPH的氧化速率(b)。HMGR活力单位: 一个活 力单位为 $1 \mathrm{~min}$ 氧化 $1 \mathrm{nmol} \mathrm{NADPH}$ 所需酶量 $(1 \mathrm{U})$ 。

DXR活性测定：参照Hasunuma等(2008)的方法 并略作修改。反应总体积 $1 \mathrm{~mL}$ 。取 $980 \mathrm{~mL}$ Tris- $\mathrm{HCl}$ 缓冲液 $\left(150 \mathrm{mmol} \cdot \mathrm{L}^{-1}, \mathrm{pH}\right.$ 值 7.5$)$, 加入 $20 \mu \mathrm{L}$ 酶液。 立即计时, 用紫外分光光度计在 $340 \mathrm{~nm}$ 处检测 $\mathrm{NADPH}$ 的氧化情况, 每隔10 s检测一次, 连续测定 $5 \mathrm{~min}$, 测得无底物DXP的情况下NADPH的氧化速 率 $(a)$ 。反应体系同上, 取 $955 \mu \mathrm{L}$ 反应液, 加 $20 \mu \mathrm{L}$ 酶 液, 再加 $25 \mu \mathrm{L}$ DXP母液。操作步骤同上, 测得有 DXP情况下的NADPH的氧化速率 $(b)$ 。DXR活力单 位: 一个活力单位为 $1 \mathrm{~min}$ 氧化 $1 \mathrm{nmol} \mathrm{NADPH}$ 所需 酶量 $(1 \mathrm{U})$ 。

蛋白质含量测定：参照Bradford (1976)的方法 进行测定。

LOX酶液提取: 称取 $0.5 \mathrm{~g}$ 叶片剪碎, 用 $9 \mathrm{~mL}$ 
Tris- $\mathrm{HCl}$ 缓冲液 $\left(100 \mathrm{mmol} \cdot \mathrm{L}^{-1}, \mathrm{pH}\right.$ 值 7.8)冰浴研磨至 匀浆, $10000 \mathrm{r} \cdot \min ^{-1}$ 离心 $10 \min \left(4{ }^{\circ} \mathrm{C}\right)$, 得到上清液。

LOX活性的测定参照Hatanaka (1993)的方法并 做修改。 $3.25 \mathrm{~mL}$ 反应体系中含有 $3.0 \mathrm{~mL}$ 醋酸缓冲液 $\left(100 \mathrm{mmol} \cdot \mathrm{L}^{-1}, \mathrm{pH}\right.$ 值 5.0$) 、 0.2 \mathrm{~mL}$ 底物和 $0.05 \mathrm{~mL}$ 酶 液, 测定在 $3 \mathrm{~min}$ 内 $234 \mathrm{~nm}$ 波长处吸光度的变化。LOX 活力单位: $234 \mathrm{~nm}$ 波长处, 以亚油酸为底物, $1 \mathrm{~min}$ 反应体系吸光度增加 0.1 为 1 个活力单位 $(1 \mathrm{U})$ 。

\subsection{VOCs采集及分析方法}

在9:00-11:00, 采用动态顶空气体循环采集法 采集“波叶金桂” VOCs, 气体流量设置为 $0.1 \mathrm{~m}^{3} \cdot \mathrm{min}^{-1}$, 采样3 $\mathrm{min}$ 。VOCs成分分析采用TDS-GC-MS法。 仪器正常工作条件参数设置参照 Gao等(2005)的方 法。TDS (TD3, GERSTEL, Mulheim, Germany)工作 条件: 载气压力 $20 \mathrm{kPa}$; 进样口温度 $250{ }^{\circ} \mathrm{C}$; 热脱 附温度 $250{ }^{\circ} \mathrm{C}$, 保持 $10 \mathrm{~min}$; 冷阱温度 $-100{ }^{\circ} \mathrm{C}$, 保 持 $3 \mathrm{~min}$; 冷阱进样时温度骤然升至 260 。 GC (7890A, Agilent, Delaware, USA)工作条件: 色谱柱为 $30 \mathrm{~m} \times$ $250 \mu \mathrm{m} \times 0.25 \mu \mathrm{m}$ 的HP-5MS柱; 升温程序: 初始温 度 $40{ }^{\circ} \mathrm{C}$, 保持 $4 \mathrm{~min}$ 后, 以 $6{ }^{\circ} \mathrm{C} \cdot \mathrm{min}^{-1}$ 速率升至 $250{ }^{\circ} \mathrm{C}$, 保持 $3 \mathrm{~min}$ 后, 以 $10{ }^{\circ} \mathrm{C} \cdot \mathrm{min}^{-1}$ 的速率升至 $270{ }^{\circ} \mathrm{C}$, 保持 $5 \mathrm{~min}$ 。MS (5975C, Agilent, Delaware, USA)工作条件: 电离方式为 $\mathrm{EI}$; 电子能量为 $70 \mathrm{eV}$, 原子质量范围: $28-450$; 接口温度 $280{ }^{\circ} \mathrm{C}$; 离子源 温度为 $230{ }^{\circ} \mathrm{C}$; 四级杆温度 $150{ }^{\circ} \mathrm{C}$ 。

\section{5 数据分析}

所有数据均为 5 次重复的平均值土标准误差。利 用Oringin 9.0软件进行数据处理、图表制作和统计 分析, 统计方法采用单因素方差分析, 进行Turkey 多重比较 $(p<0.05)$ 。采用双因素方差分析法分析高 温 $\times$ 干旱处理的交互作用。通过TDS-GC-MS技术分 析, 获得VOCs总离子流色谱图, 采用NIST2008谱 库并进行定性分析组分, 以色谱峰的峰面积表示成 分的相对含量。

\section{2 结果和分析}

\section{1 干旱、高温及协同胁迫对葡萄糖含量的影响}

图1显示了干旱、高温及协同胁迫对“波叶金桂” 叶片葡萄糖含量的影响。干旱胁迫下葡萄糖含量呈 现持续上升趋势, 在重度干旱胁迫下达到最高值, 比对照增加了 $13.8 \%(p<0.05)$; 高温胁迫下葡萄糖 含量减少，比对照降低了 $15.5 \%(p<0.05)$; 协同胁

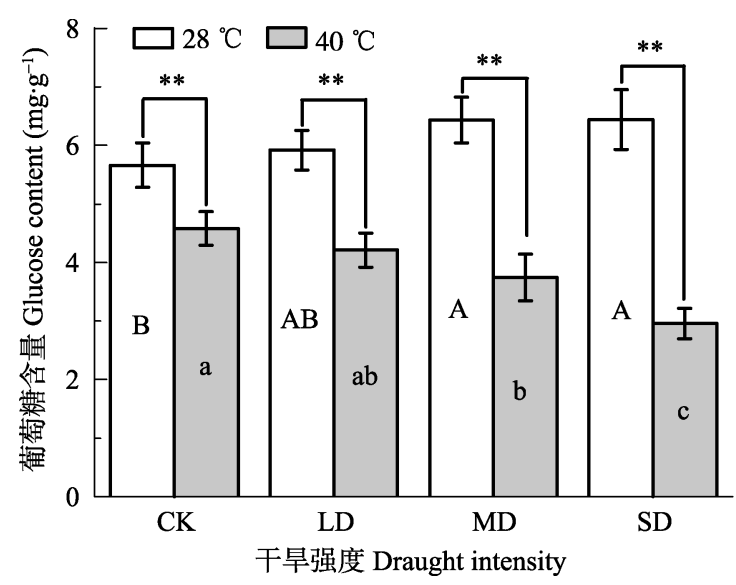

图1干旱高温处理对波叶“波叶金桂”叶片葡萄糖含量的影 响(平均值土标准误差, $n=5$ )。不同大写字母表示干旱处理的 差异显著, 不同小写字母表示高温处理的差异显著 $(p<0.05$, 根据LSD测验)。**, $p<0.01$ 。CK, 对照; LD, 轻度干旱; MD, 中度干旱; SD, 重度干旱。

Fig. 1 Effects of drought and heat stress on glucose content in leaves of Osmanthus fragrans cv. 'Boyejingui' (mean $\pm S E, n=$ 5). Different uppercase letters indicate significant differences of drought and different lowercase letters denote statistically significant differences of heat stress treatment $(p<0.05$, according to LSD test). $p<0.01$. CK, control; LD, light drought; MD, moderate drought; $\mathrm{SD}$, severe drought.

迫下比高温胁迫下降低幅度大，与对照相比，轻 度、中度、重度协同胁迫分别减少了 $25.6 \%$ 、33.9\% 和 $47.7 \%(p<0.05)$, 表明高温和协同胁迫导致“波叶 金桂'叶片葡萄糖含量减少。

\section{2 干旱、高温及协同胁迫对果糖含量的影响}

干旱、高温及协同胁迫对 “波叶金桂”叶片果糖 含量的影响见图2。在干旱胁迫下果糖含量变化不 明显; 高温胁迫下果糖含量比对照降低了 $15.4 \%(p$ $<0.05$ ); 果糖含量在协同胁迫下持续性下降, 与对 照相比, 轻度、中度和重度协同胁迫下分别降低了 $19.3 \% 、 27.5 \%$ 和 $46.4 \%(p<0.05)$, 下降幅度显著大 于单一高温胁迫, 显著影响果糖的合成与分解。

\section{3 干旱、高温及协同胁迫对蔗糖含量的影响}

图3显示了干旱、高温及协同胁迫对“波叶金桂” 叶片蔗糖含量的影响。蔗糖含量随着干旱胁迫强度 的增强呈现先升高后降低的趋势, 分别在轻度和重 度干旱胁迫达到最高值和最低值, 与对照相比分别 增加了 $12.3 \%(p<0.05)$ 和减少了 $15.3 \%(p<0.05)$; 高温胁迫下蔗糖含量比对照减少了 $9.8 \%(p<0.05)$; 轻度、中度、重度协同胁迫下蔗糖含量与对照相比 分别减少了 $13.6 \% 、 26.0 \%$ 和 $34.4 \%(p<0.05)$ 。轻度 干旱促进蔗糖的积累, 高温、协同胁迫促进蔗糖的 分解, 为“波叶金桂’抵御胁迫提供能量。 


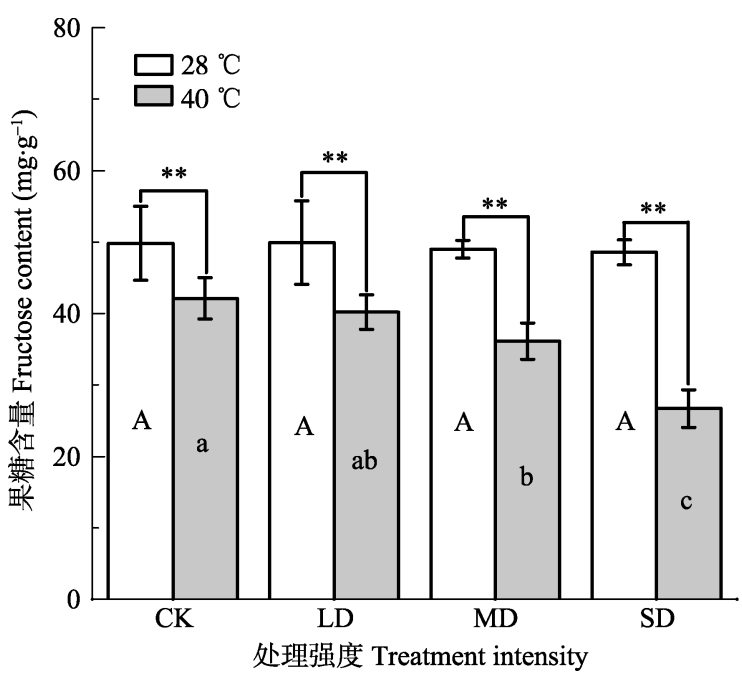

图2干旱高温处理对“波叶金桂”叶片果糖含量的影响(平均 值土标准误差, $n=5)$ 。不同大写字母表示干旱的差异显著, 不同小写字母表示高温的差异显著 $(p<0.05$, 根据LSD测 验)。**, $p<0.01$ 。 $\mathrm{CK}$, 对照; $\mathrm{LD}$, 轻度干旱; $\mathrm{MD}$, 中度干旱; $\mathrm{SD}$, 重度干旱。

Fig. 2 Effects of drought and heat stress on fructose content in leaves of Osmanthus fragrans cv. 'Boyejingui' (mean $\pm S E, n=$ 5). Different uppercase letters indicate significant differences of drought and different lowercase letters denote statistically significant differences of heat stress treatment $(p<0.05$, according to LSD test). ${ }^{* *}, p<0.01$. CK, control; LD, light processing; $\mathrm{MD}$, moderate drought; $\mathrm{SD}$, severe drought.

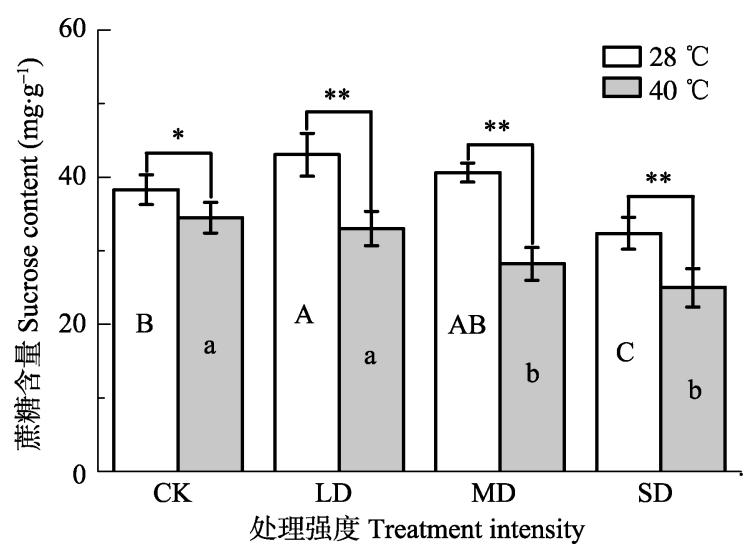

图3干旱高温处理对“波叶金桂”叶片蔗糖含量的影响(平均 值 \pm 标准误差, $n=5)$ 。不同大写字母表示干旱的差异显著, 不 同小写字母表示高温的差异显著 $(p<0.05$, 根据LSD测验 $)$ 。 **, $p<0.01$ 。CK, 对照; $\mathrm{LD}$, 轻度干旱; $\mathrm{MD}$, 中度干旱; $\mathrm{SD}$, 重度干旱。

Fig. 3 Effects of drought and heat stress on sucrose content in leaves of Osmanthus fragrans cv. 'Boyejingui' (mean $\pm S E, n=$ 5 ). Different uppercase letters indicate significant differences of drought and different lowercase letters denote statistically significant differences of heat stress treatment $(p<0.05$, according to LSD test). $p<0.01$. CK, control; LD, light drought; MD, moderate drought; $\mathrm{SD}$, severe drought.

\section{4 干旱、高温及协同胁迫对淀粉含量的影响} 从图4可以看出: 干旱、高温及协同胁迫下‘波
叶金桂’叶片淀粉含量发生了不同程度的变化。随着 干旱胁迫强度的增加, 淀粉含量表现出先上升后下 降趋势, 在重度干旱胁迫下达到最低值, 比对照减 少了 $20.6 \%(p<0.05)$; 高温胁迫下淀粉含量比对照 减少了 $14.0 \%(p<0.05)$; 与对照相比, 轻度、中度和 重度协同胁迫下淀粉含量分别降低了 $20.5 \% 、 29.9 \%$ 和 $38.2 \%(p<0.05)$, 协同胁迫下明显降低了“波叶金 桂'叶片中的淀粉含量。

\section{5 干旱、高温及协同胁迫对HMGR活性的影响}

由图5可见，随着干旱胁迫强度的增强，“波叶 金桂’叶片HMGR活性先上升后下降, 在轻度干旱 胁迫下达到最大值，与对照相比增加了 $57.1 \%(p<$ $0.05)$, 重度干旱胁迫下减少了 $22.1 \%(p<0.05)$; 高 温胁迫下HMGR活性比对照增加了 $43.2 \%(p<0.05)$; 干旱高温协同胁迫后，与对照相比，HMGR活性在 轻度协同胁迫下增加了 $52.8 \%(p<0.05)$, 在重度协 同胁迫下减少了 $37.7 \%(p<0.05)$ 。

\section{6 干旱、高温及协同胁迫对DXR活性的影响}

如图6所示，在干旱胁迫下，随着胁迫强度的 增强, “波叶金桂”叶片DXR活性呈现先上升后下降 的趋势, 与对照相比, 中度干旱胁迫下增加了 $56.7 \%(p<0.05)$, 重度干旱胁迫下略有减少; 高温 胁迫下DXR活性比对照增加了 $41.1 \%(p<0.05)$; 协

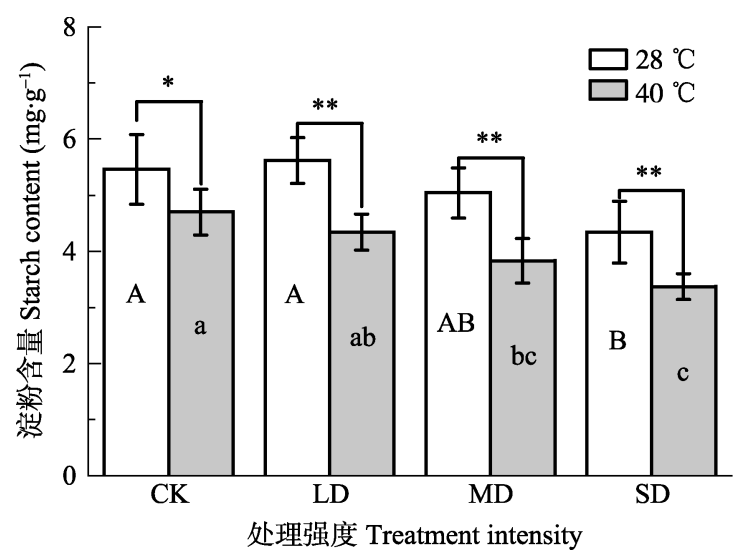

图4干旱高温处理对“波叶金桂”叶片淀粉含量的影响(平均 值土标准误差, $n=5$ )。不同大写字母表示干旱的差异显著, 不同小写字母表示高温的差异显著 $(p<0.05$, 根据LSD测 验)。**, $p<0.01$ 。CK, 对照; $\mathrm{LD}$, 轻度干旱; $\mathrm{MD}$, 中度干旱; $\mathrm{SD}$, 重度干旱。

Fig. 4 Effects of drought and heat stress on starch content in leaves of Osmanthus fragrans cv. 'Boyejingui' (mean $\pm S E, n=$ 5). Different uppercase letters indicate significant differences of drought and different lowercase letters denote statistically significant differences of heat stress treatment $(p<0.05$, according to LSD test). ${ }^{* *}, p<0.01$. CK, control; LD, light drought; MD, moderate drought; $\mathrm{SD}$, severe drought. 


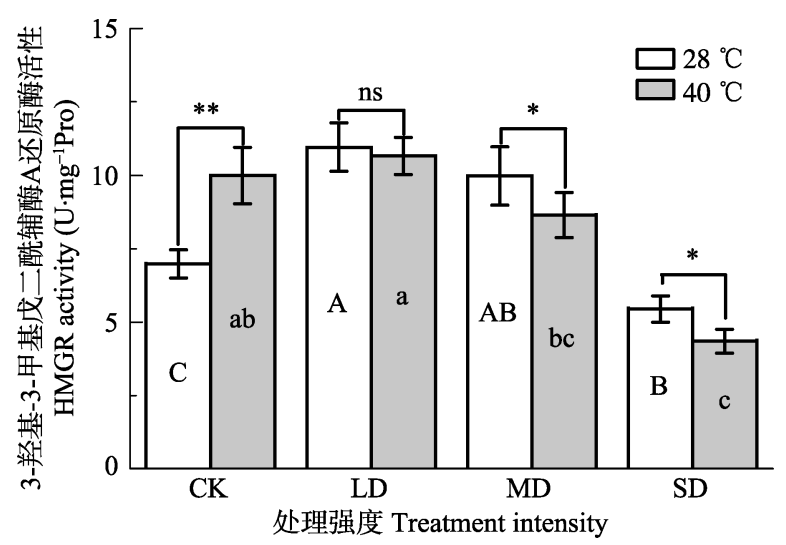

图5 干旱高温处理对“波叶金桂”叶片3-羟基-3-甲基戊二酸 单酰辅酶A还原酶活性的影响(平均值土标准误差, $n=5$ )。不 同大写字母表示干旱的差异显著, 不同小写字母表示高温 的差异显著 $(p<0.05$, 根据LSD测验 $)$ 。**, $p<0.01$ 。CK, 对 照; LD, 轻度干旱; MD, 中度干旱; $\mathrm{SD}$, 重度干旱。

Fig. 5 Effects of drought and heat stress on 3-hydroxy-3methylglutaryl CoA reductase (HMGR) activity in leaves of Osmanthus fragrans cv. 'Boyejingui' (mean $\pm S E, n=5$ ). Different uppercase letters indicate significant differences of drought and different lowercase letters denote statistically significant differences of heat stress treatment $(p<0.05$, according to LSD test). ${ }^{* *}, p<0.01$. CK, control; LD, light drought; MD, moderate drought; $\mathrm{SD}$, severe drought.

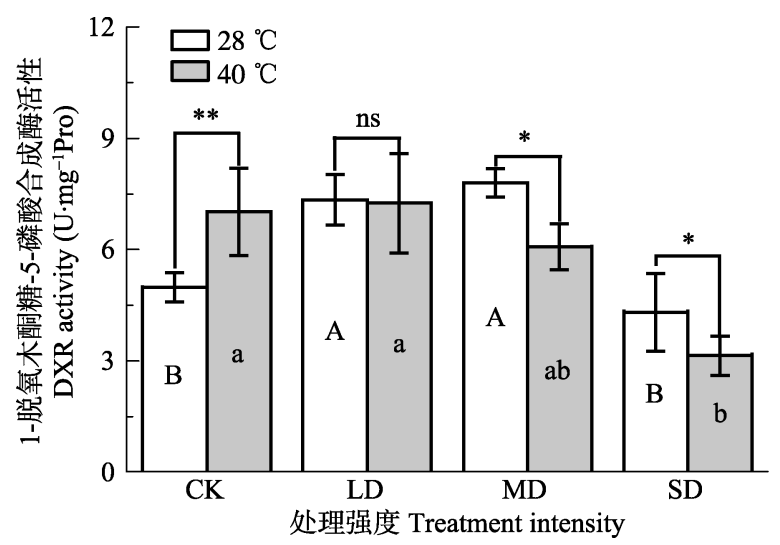

图6干旱高温处理对 ‘波叶金桂” 叶片1-脱氧木酮糖-5-磷酸 还原酶活性的影响(平均值土标准误差, $n=5$ )。不同大写字母 表示干旱的差异显著, 不同小写字母表示高温的差异显著 $(p$ $<0.05$, 根据LSD测验)。**, $p<0.01$ 。CK, 对照; LD, 轻度干 旱; $\mathrm{MD}$, 中度干旱; $\mathrm{SD}$, 重度干旱。

Fig. 6 Effects of drought and heat stress on 1-deoxyD-xylulose 5-phosphate reductoisomerase (DXR) activity in leaves of Osmanthus fragrans cv. 'Boyejingui' (mean $\pm S E, n=$ 5). Different uppercase letters indicate significant differences of drought and different lowercase letters denote statistically significant differences of $\mathrm{d}$ heat stress treatment $(p<0.05$, according to LSD test). ${ }^{* *}, p<0.01$;. CK, control; LD, light drought; $\mathrm{MD}$, moderate drought; $\mathrm{SD}$, severe drought.

同胁迫下DXR活性呈现先升高后下降的趋势, 轻度 协同胁迫下与对照相比增加了 $45.6 \%(p<0.05)$, 重 度协同胁迫下降低了 $36.9 \%(p<0.05)$ 。

\section{7 干旱、高温及协同胁迫对LOX活性的影响}

从图7可以看出，干旱、高温及协同胁迫后, “波 叶金桂'叶片LOX活性发生了不同程度的变化。随着 干旱胁迫强度的增强, LOX活性呈上升趋势, 重度 干旱胁迫下比对照增加了 $55.4 \%(p<0.05)$; 高温胁 迫下LOX活性比对照增加了 $39.7 \%(p<0.05)$; 轻 度、中度和重度协同胁迫下与对照相比分别增加了 $60.9 \% 、 67.7 \%$ 和 $39.8 \%(p<0.05)$ 。

\section{8 干旱、高温及协同胁迫对挥发物的影响}

干旱、高温和协同胁迫, “波叶金桂”叶片VOCs 种类和含量发生显著变化, VOCs 共鉴定出 23 种化 合物(表1)。随着干旱胁迫强度的增加, VOCs释放量 呈上升趋势, 中度和重度干旱胁迫下VOCs释放量 分别比对照增加了 $24.1 \%$ 和 $22.8 \%(p<0.05)$ 。干旱胁 迫下萜烯类化合物释放量呈现先增加后减少的趋 势, 轻度和中度干旱胁迫下萜烯类化合物释放量分 别比对照增加了 $16.8 \%$ 和 $37.9 \%(p<0.05)$, 重度干 旱胁迫下减少了 $12.1 \%(p<0.05)$; 干旱胁迫下醛类 化合物释放量分别比对照增加了 $35.3 \% 、 46.8 \%$ 和 $124.5 \%(p<0.05)$, 诱导释放新增苯基丁醛和辛烯 醛。高温胁迫醛类、萜烯类和酯类化合物分别比对 照增加了 $83.6 \%$ 、32.3\%和70.3\% $(p<0.05)$ 。同时诱

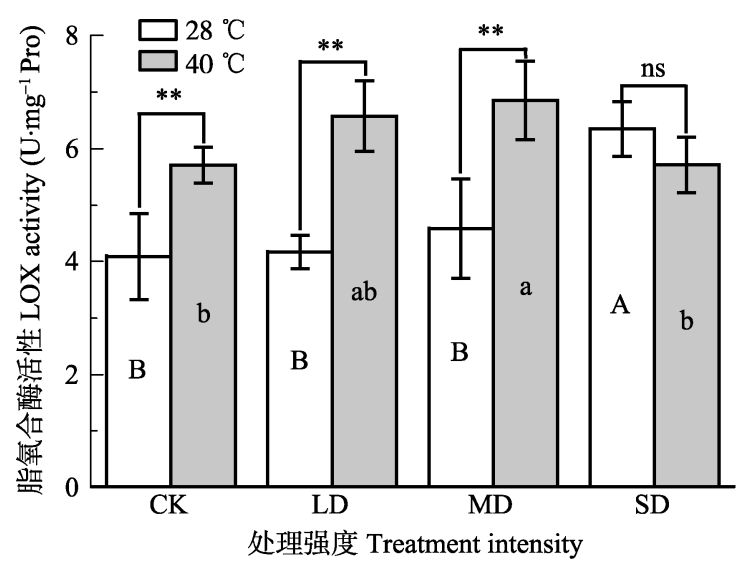

图7干旱高温处理对“波叶金桂”叶片脂氧合酶活性的影响 (平均值 \pm 标准误差, $n=5$ )。不同大写字母表示干旱的差异显 著, 不同小写字母表示高温的差异显著 $(p<0.05$, 根据LSD 测验)。*, $p<0.05 ; * *, p<0.01 ;$ 。 CK, 对照; LD, 轻度干旱; $\mathrm{MD}$ ，中度干旱; $\mathrm{SD}$, 重度干旱。

Fig. 7 Effects of drought and heat stress on lipoxygenase (LOX) activity in leaves of Osmanthus fragrans cv. 'Boyejingui' (mean $\pm S E, n=5$ ). Different uppercase letters indicate significant differences of different lowercase letters denote statistically significant differences of from drought and heat stress treatment ( $p<0.05$, according to LSD test). ${ }^{* *}, p<0.01$. CK, control; LD, light drought; $\mathrm{MD}$, moderate drought; $\mathrm{SD}$, severe drought. 
表1 波叶金桂'叶片挥发性有机化合物的主要成分(峰面积, $A \times 10^{5} \cdot 10 \mathrm{~g}^{-1}$ )(平均值土标准误差)

Table 1 The main components of the volatile organic compounds (VOCs) from the leaf of Osmanthus fragrans 'Boyejingui' (peak area, $A \times 10^{5} \cdot 10 \mathrm{~g}^{-1}$ ) $($ mean $\pm S E)$

\begin{tabular}{|c|c|c|c|c|c|c|c|c|c|c|}
\hline \multirow{2}{*}{$\begin{array}{l}\text { 序号 } \\
\text { No. }\end{array}$} & \multirow{2}{*}{$\begin{array}{l}\text { 挥发性有机物 } \\
\text { Volatile organic compounds }\end{array}$} & \multirow{2}{*}{$\begin{array}{l}\text { 分子式 } \\
\text { Chemical } \\
\text { formula }\end{array}$} & \multicolumn{4}{|c|}{$28{ }^{\circ} \mathrm{C}$} & \multicolumn{4}{|c|}{$40{ }^{\circ} \mathrm{C}$} \\
\hline & & & $\begin{array}{c}\text { 对照 } \\
\text { Control }\end{array}$ & $\begin{array}{c}\text { 轻度干旱 } \\
\text { Light } \\
\text { drought }\end{array}$ & $\begin{array}{c}\text { 中度干旱 } \\
\text { Moderate } \\
\text { drought }\end{array}$ & $\begin{array}{c}\text { 重度干旱 } \\
\text { Severe } \\
\text { drought }\end{array}$ & $\begin{array}{c}\text { 对照 } \\
\text { Control }\end{array}$ & $\begin{array}{c}\text { 轻度干旱 } \\
\text { Light } \\
\text { drought }\end{array}$ & $\begin{array}{c}\text { 中度干旱 } \\
\text { Moderate } \\
\text { drought }\end{array}$ & $\begin{array}{c}\text { 重度干旱 } \\
\text { Severe } \\
\text { drought }\end{array}$ \\
\hline 1 & 己烯醛 3-Hexenal & $\mathrm{C}_{6} \mathrm{H}_{10} \mathrm{O}$ & $3.33 \pm 0.23$ & $0.58 \pm 0.65$ & $2.27 \pm 0.12$ & - & $3.61 \pm 0.26$ & - & - & $1.15 \pm 0.05$ \\
\hline 2 & $\begin{array}{l}\text { 2-甲基-4-戊烯醛 } \\
\text { 2-Methyl-4-pentenal }\end{array}$ & $\mathrm{C}_{6} \mathrm{H}_{10} \mathrm{O}$ & $0.99 \pm 0.11$ & $2.36 \pm 0.23$ & - & $5.97 \pm 0.35$ & - & $2.88 \pm 0.12$ & $3.14 \pm 0.16$ & $1.69 \pm 0.13$ \\
\hline 3 & 2-已烯醛 (E)-2-Hexenal & $\mathrm{C}_{6} \mathrm{H}_{10} \mathrm{O}$ & $2.48 \pm 0.18$ & $2.14 \pm 0.23$ & $2.54 \pm 0.21$ & $8.67 \pm 1.14$ & $4.53 \pm 0.54$ & $4.35 \pm 0.08$ & $8.01 \pm 0.24$ & $7.03 \pm 0.19$ \\
\hline 4 & 苯基丁醛 4-Phenylbutanal & $\mathrm{C}_{10} \mathrm{H}_{12} \mathrm{O}$ & - & $1.85 \pm 0.11$ & - & - & - & $5.48 \pm 0.13$ & $2.58 \pm 0.06$ & $2.74 \pm 0.06$ \\
\hline 5 & 山梨醛 Sorbaldehyde & $\mathrm{C}_{6} \mathrm{H}_{8} \mathrm{O}$ & $1.08 \pm 0.06$ & $2.82 \pm 0.08$ & $1.90 \pm 0.04$ & $3.05 \pm 0.64$ & $1.80 \pm 0.08$ & - & $2.61 \pm 0.11$ & $2.33 \pm 0.08$ \\
\hline 6 & 辛烯醛 2-Ethylhexenal & $\mathrm{C}_{8} \mathrm{H}_{14} \mathrm{O}$ & - & $1.91 \pm 0.04$ & $4.86 \pm 0.81$ & - & $3.77 \pm 0.12$ & $1.37 \pm 0.06$ & $0.67 \pm 0.02$ & - \\
\hline 7 & 壬醛 n-Nonanal & $\mathrm{C}_{9} \mathrm{H}_{18} \mathrm{O}$ & - & - & - & - & $0.76 \pm 0.02$ & $1.21 \pm 0.04$ & $0.90 \pm 0.05$ & $0.53 \pm 0.02$ \\
\hline 8 & $\begin{array}{l}\text { 反-3-己烯醇 } \\
\text { trans-3-Hexenol }\end{array}$ & $\mathrm{C}_{6} \mathrm{H}_{12} \mathrm{O}$ & $6.80 \pm 0.45$ & $8.07 \pm 0.62$ & $7.85 \pm 0.67$ & $4.12 \pm 0.35$ & $9.26 \pm 1.61$ & $2.50 \pm 0.27$ & $5.38 \pm 1.01$ & $3.20 \pm 0.32$ \\
\hline 9 & $\begin{array}{l}(3 \mathrm{E}) \text {-3-壬烯醇 } \\
\text { (3E)-3-Nonen-1-ol }\end{array}$ & $\mathrm{C}_{9} \mathrm{H}_{18} \mathrm{O}$ & - & - & - & - & - & - & $1.24 \pm 0.07$ & $1.17 \pm 0.11$ \\
\hline 10 & $\begin{array}{l}\text { 2-乙基己醇 } \\
\text { 2-Ethylhexan-1-ol }\end{array}$ & $\mathrm{C}_{8} \mathrm{H}_{18} \mathrm{O}$ & $4.28 \pm 0.14$ & $1.25 \pm 0.08$ & - & $1.93 \pm 0.07$ & - & $8.29 \pm 0.61$ & $2.08 \pm 0.10$ & $2.15 \pm 0.09$ \\
\hline 11 & 反罗勒烯 Ocimene & $\mathrm{C}_{10} \mathrm{H}_{16}$ & $1.65 \pm 0.06$ & $1.53 \pm 0.11$ & $2.02 \pm 0.08$ & $1.85 \pm 0.05$ & $1.55 \pm 0.08$ & - & $0.80 \pm 0.02$ & - \\
\hline 12 & 薄荷烯 cis-p-Menthane & $\mathrm{C}_{10} \mathrm{H}_{20}$ & $3.38 \pm 0.04$ & - & $2.03 \pm 0.06$ & - & $1.50 \pm 0.12$ & $2.48 \pm 0.21$ & - & $1.08 \pm 0.05$ \\
\hline 13 & 柠檬烯 Limonene & $\mathrm{C}_{10} \mathrm{H}_{16}$ & $3.83 \pm 0.07$ & $1.42 \pm 0.12$ & $1.61 \pm 0.12$ & $1.74 \pm 0.10$ & $3.29 \pm 0.29$ & $1.65 \pm 0.15$ & $1.67 \pm 0.03$ & $0.94 \pm 0.04$ \\
\hline 14 & 罗勒烯Ocimene & $\mathrm{C}_{10} \mathrm{H}_{16}$ & $0.18 \pm 0.01$ & $3.25 \pm 0.24$ & $2.58 \pm 0.22$ & $1.44 \pm 0.14$ & $1.40 \pm 0.10$ & - & $0.94 \pm 0.05$ & - \\
\hline 15 & $\alpha$-蒎烯alpha-Pinene & $\mathrm{C}_{10} \mathrm{H}_{16}$ & $0.07 \pm 0.01$ & $2.68 \pm 0.16$ & $3.13 \pm 0.02$ & $2.52 \pm 0.09$ & $5.24 \pm 0.34$ & $4.83 \pm 0.37$ & $3.60 \pm 0.34$ & $2.69 \pm 0.27$ \\
\hline 16 & 紫苏烯 Perillen & $\mathrm{C}_{10} \mathrm{H}_{14} \mathrm{O}$ & $0.34 \pm 0.04$ & $0.53 \pm 0.05$ & $1.05 \pm 0.11$ & $1.60 \pm 0.06$ & $1.03 \pm 0.02$ & $0.63 \pm 0.01$ & $0.54 \pm 0.02$ & - \\
\hline 17 & 长叶烯 Longifolene & $\mathrm{C}_{15} \mathrm{H}_{24}$ & $1.77 \pm 0.13$ & $3.69 \pm 0.05$ & $2.05 \pm 0.23$ & $0.71 \pm 0.03$ & $0.83 \pm 0.01$ & $1.46 \pm 0.04$ & $1.03 \pm 0.02$ & $0.88 \pm 0.04$ \\
\hline 18 & 丁香烯 $\pi$ Caryophyllen & $\mathrm{C}_{15} \mathrm{H}_{24}$ & - & - & - & - & - & $1.07 \pm 0.05$ & - & - \\
\hline 19 & $\begin{array}{l}\text { 顺-3-乙酸叶醇酯 } \\
\text { cis-3-Hexenyl acetate }\end{array}$ & $\mathrm{C}_{8} \mathrm{H}_{14} \mathrm{O}_{2}$ & $1.55 \pm 0.06$ & $1.61 \pm 0.86$ & $2.25 \pm 0.61$ & $4.73 \pm 1.37$ & $6.11 \pm 1.01$ & $2.63 \pm 0.31$ & $2.20 \pm 0.92$ & $4.09 \pm 0.56$ \\
\hline 20 & $\begin{array}{l}\text { 丙烯酸正己酯 } \\
\text { Hexyl acrylate }\end{array}$ & $\mathrm{C}_{9} \mathrm{H}_{16} \mathrm{O}_{2}$ & $1.90 \pm 0.09$ & - & - & - & - & $2.58 \pm 0.18$ & $1.55 \pm 0.02$ & $1.08 \pm 0.04$ \\
\hline 21 & $\begin{array}{l}\text { 异丁酸庚酯 } \\
\text { Heptyl isobutyrate }\end{array}$ & $\mathrm{C}_{11} \mathrm{H}_{22} \mathrm{O}_{2}$ & - & - & $0.96 \pm 0.03$ & $5.66 \pm 0.63$ & $2.45 \pm 0.23$ & $6.00 \pm 0.93$ & $3.10 \pm 0.43$ & $2.47 \pm 0.41$ \\
\hline 22 & 丁酸庚酯 Heptyl butyrate & $\mathrm{C}_{11} \mathrm{H}_{22} \mathrm{O}_{2}$ & $1.39 \pm 0.05$ & $1.31 \pm 0.03$ & $4.22 \pm 0.08$ & $2.05 \pm 0.39$ & $5.02 \pm 0.71$ & $4.40 \pm 1.21$ & $2.79 \pm 0.94$ & $2.18 \pm 0.52$ \\
\hline \multirow[t]{2}{*}{23} & 丁酸丁酯 Butyl butyrate & $\mathrm{C}_{8} \mathrm{H}_{16} \mathrm{O}_{2}$ & $3.87 \pm 0.14$ & $3.07 \pm 0.54$ & $5.93 \pm 0.35$ & $1.71 \pm 0.48$ & $1.25 \pm 0.08$ & - & - & - \\
\hline & 合计 & & 38.89 & 40.07 & 48.25 & 47.75 & 53.4 & 52.81 & 44.83 & 37.37 \\
\hline
\end{tabular}

-, 未检测到化合物。

- , the compound was not detected

导新增辛烯醛、壬醛和异丁酸庚酯3种新组分。协 同胁迫萜烯类化合物释放量减少，醛类化合物释放 量增加，轻度、中度和重度协同胁迫下醛类化合物 释放量分别比对照增加了 $94.0 \% 、 127.3 \%$ 和 $96.3 \%(p$ $<0.05)$, 新诱导出丁香烯、壬醛、3-壬烯醇、辛烯 醛、苯基丁醛和异丁酸庚酯。

\section{3 讨论}

NSC 是参与植物生命代谢的重要物质，作为 “可移动碳库”为植物体生长发育提供碳源和能源, 其碳库大小和组分含量可反映出 NSC 在植物体的
碳代谢和碳平衡(潘庆民等，2002; 李蟠等，2008), 在逆境条件下维持碳平衡是树木抵抗胁迫的应对 机制(McDowell et al., 2008; Choat et al., 2012)。相关 研究表明, 一定程度干旱胁迫下植物积累可溶性糖 进行渗透调节, 但也有研究表明, 干旱胁迫能够导 致植物叶片气孔关闭, 减小光合速率，可能迫使植 物耗竭NSC储备, 导致因碳饥饿而死亡(Maguire \& Kobe, 2015)。温度升高能够加强细胞呼吸作用，消 耗体内大量的可溶性糖和淀粉, 为抵御高温胁迫提 供能量, 最终出现负碳平衡, 导致NSC含量减少。 Trifilò等(2017)研究发现月桂(Laurus nobilis)长期轻 
度缺水使植株生长速度减慢, 可溶性NSC含量降低, 淀粉含量增加; 热处理导致西黄松和花旗松幼苗葡 萄糖和果糖含量增加, 淀粉含量减少, 总 NSC和蔗 糖含量没有受到热处理的影响(Marias et al., 2017); 赵超等(2017)研究发现, 木薯(Manihot esculenta) $\mathrm{NSC}$ 含量在轻度干旱胁迫下升高, 而在严重干旱胁 迫下大幅度降低。本研究结果显示, 随着干旱胁迫 强度的增强, 葡萄糖含量增加, 淀粉含量降低, 与 Trifilo等(2017)的研究结果不一致, 可能是因为淀粉 降解为可溶性糖进行渗透调节。说明“波叶金桂’通 过积累葡萄糖来调节体内细胞渗透势, 保持一定含 水量, 缓解干旱胁迫造成的不利影响, 从而保障“波 叶金桂'正常生理活动来适应和抵御干旱胁迫(Klein et al., 2014)。葡萄糖含量的提高一方面来源于蔗糖 和淀粉的降解(图2, 图3); 另一方面是通过光合作 用途径合成。高温胁迫后, “波叶金桂’体内可溶性糖 和淀粉含量减少，并在协同胁迫后持续性下降，协 同胁迫后的研究结果与穆䔉蓁(2015)研究结果不一 致, 原因可能是实验设计不一致, 穆蓁蓁(2015)的 对照组是灌水和喷水处理。高温和干旱高温协同胁 迫, 一方面导致呼吸速率加强, 消耗大量可溶性糖, 同时还形成应激防御物质(表1), 导致NSC所有组分 含量显著下降; 另一方面协同胁迫可能导致光合器 官遭到破坏, 使光合作用受到抑制, 可溶性糖合成 降低(Silva et al., 2010)。

植物VOCs 是体内重要的次生代谢产物, 在抵 御环境胁迫中发挥着重要的抗氧化作用(Loreto \& Schnitzler, 2010; Silva et al., 2010; Jud et al., 2016)。 刘芳等(2013)研究迷迭香(Rosmarinus officinalis)发 现干旱胁迫导致VOCs释放总量减少, 但种类增加, 萜烯类化合物和绿叶挥发物相对含量显著增加; Hartikainen等(2009)研究欧洲山杨(Populus tremula) 发现, 温度升高显著增加单萜和绿叶挥发物释放量, 但在罗勒(Ocimum basilicum)中萜烯类化合物呈现 降低趋势(程璐璐等, 2015)。HMGR和DXR活性调控 着萜烯类化合物的合成量, 在防御反应中发挥重要 应激防御作用。Morshedloo等(2017)研究发现, 轻度 和中度水分胁迫下牛至(Origanum vulgare)精油含 量显著增加, 同时HMGR转录上调。本研究中, 萜 烯类化合物释放量与HMGR、DXR活性变化趋势基 本一致(表1), 说明HMGR和DXR活性能够调控萜 烯类化合物释放量。在干旱胁迫下“波叶金桂”通过
释放萜烯类化合物防止活性氧大量累积，降低氧化 胁迫的伤害, 发挥应激保护作用(Vickers et al., 2009)。同时高温能诱导提高HMGR和DXR活性促 使萜烯类化合物合成并释放，有助于膜的稳定性 (Arab et al., 2016)。在重度干旱胁迫下萜烯类化合物 减少, HMGR和DXR活性受到抑制, 也可能是严重 干旱导致气孔关闭, 萜烯类化合物的释放通道受到 阻碍。协同胁迫处理萜烯类化合物释放量降低, 一 方面是HMGR和DXR活性受到抑制; 另一方面可能 是协同胁迫导致光合产物 NSC含量减少, 供给合成 挥发物途径的碳源减少, 影响到萜烯类化合物的生 物合成。

GLVs 是由脂氧合酶 (LOX) 催化不饱和脂肪酸 形成的含氧VOCs, 是植物应激反应过程中产生的 一类具有抵御能力的物质(Santino et al., 2010), 在 参与植物防御机制和应激适应中发挥着重要作用 (Hatanaka, 1993; Loreto \& Schnitzler, 2010)。Nahar 等(2015)研究发现, 高温胁迫显著增加了绿豆 (Vigna radiata) 的 LOX 活性; 干旱胁迫下小麦 (Triticum aestivum) 各器官LOX活性显著升高(马超 等, 2017); Vitale等(2008)发现, 干旱胁迫明显诱导 冬青栎(Quercus ilex) LOX活性增加, 同时(E)-2-己 烯醇和(Z)-3-己烯醛释放量也相应增加。本实验结 果显示, 重度干旱胁迫下 “波叶金桂” LOX活性显著 增加, 诱导GLVs释放量相应增加, 可能是“波叶金 桂, 细胞膜受到损伤, 活性氧积累触发和刺激LOX 途径, 促进GLVs释放以清除活性氧, 发挥抗氧化作 用(Agrawal et al., 2009)。高温有利于提高LOX活性, 增加GLV释放量; 协同胁迫严重破坏细胞膜结构, 诱导细胞膜脂质过氧化, 醛类化合物释放量显著增 加(表1)。

植物体内的初生代谢和次生代谢途径处于动 态平衡, $\mathrm{NSC}$ 是合成次生代谢产物的主要来源, VOCs的排放可能会大幅减少植物的固碳量(Dicke \& Loreto, 2010; Peñuelas \& Staudt, 2010; Copolovici et al., 2014)。本研究中, 干旱胁迫下 ‘波叶金桂”通过 蔗糖和淀粉降解积累葡萄糖维持正常膨压进行渗 透调节; 同时, 还给次生代谢途径供给碳源合成萜 烯类化合物(表1), 以此降低活性氧对“波叶金桂”细 胞膜的伤害。高温胁迫加强呼吸作用, 消耗可溶性 糖和淀粉为萜烯类化合物的合成提供能量与碳源, 萜烯类化合物释放量显著增加; 协同胁迫导致细胞

www.plant-ecology.com 
结构被破坏，碳摄取和利用受到限制，供应到次生 代谢途径的碳源和能源减少, 最终萜烯类化合物的 合成减少, “波叶金桂”体内活性氧大量积累以及细 胞膜脂质过氧化, 在中度和重度协同胁迫下对“波 叶金桂, 细胞膜造成严重伤害, 从而导致GLVs释放 量增加。

综上所述, NSC既为植物自我调节提供能源和 碳源, 同时又作为渗透调节物质进行渗透调节。干 旱胁迫下 “波叶金桂”通过降解淀粉和蔗糖积累葡萄 糖，进行渗透调节维持正常膨压，同时提高次生代 谢酶活性调控萜烯类化合物大量合成，从而抵御干 旱胁迫。重度干旱胁迫导致GLVs释放量增加, “波叶 金桂”细胞膜已经受到伤害; 高温胁迫下 “波叶金桂” 呼吸作用加快, 可溶性糖和淀粉降解, 为抵御胁迫 提供能量和碳源, 同时提高次生代谢酶活性, 促进 萜烯类化合物合成，从而抵御高温胁迫; 协同胁迫 后, 可溶性糖含量明显下降, 菬烯类化合物的生物 合成受阻，“波叶金桂”通过提高LOX活性合成大量 GLVs; 中度和重度协同胁迫对“波叶金桂”的伤害已 经超过“波叶金桂”自身生理生化调节的阈值, 细胞 膜已经严重受损并导致组织损伤, 无法正常发挥保 护机能。

\section{参考文献}

Agrawal SB, Singh S, Agrawal M (2009). Ultraviolet-B induced changes in gene expression and antioxidants in plants. Advances in Botanical Research, 52, 47-86.

Arab L, Kreuzwieser J, Kruse J, Zimmer I, Ache P, Alfarraj S, Al-Rasheid KAS, Schnitzler JP, Hedrich R, Rennenberg H (2016). Acclimation to heat and drought-Lessons to learn from the date palm (Phoenix dactylifera). Environmental \& Experimental Botany, 125, 20-30.

Bourtsoukidis E, Kawaletz H, Radacki D, Schütz S, Hakola H, Hellén H, Noe S, Mölder I, Ammer C, Bonn B (2014). Impact of flooding and drought conditions on the emission of volatile organic compounds of Quercus robur and Prunus serotina. Trees, 28, 193-204.

Bradford MM (1976). A rapid and sensitive method for the quantitation of microgram quantities of protein utilizing the principle of protein-dye binding. Analytical Biochemistry, 72, 248-254.

Chen KC (2013). The warming trend and the distribution of the seasons in Hangzhou from 1961 to 2012. Chinese Agricultural Science Bulletin, 29, 345-350. [陈柯辰 (2013). 1961-2012年杭州的升温趋势和四季分配之变化.中国 农学通报, 29, 345-350.]
Cheng LL, Chen M, Leng PS, Hu ZH (2015). Effect of different temperature levels on the emission of terpenoid volatile compounds in Ocimum basilicum 'Purple Ruffles'. Journal of Beijing University of Agriculture, 30(2), 78-82. [程 璐璐，陈敏，冷平生，胡增辉 (2015). 不同温度对紫罗 勒萜烯类挥发物释放的影响. 北京农学院学报, 30(2), 78-82.]

Choat B, Jansen S, Brodribb TJ, Cochard H, Delzon S, Bhaskar R, Bucci SJ, Feild TS, Gleason SM, Hacke UG, Jacobsen AL, Lens F, Maherali H, Martínez-Vilalta J, Mayr S, Mencuccini M, Mitchell PJ, Nardini A, Pittermann J, Pratt RB, Sperry JS, Westoby M, Wright IJ, Zanne AE (2012). Global convergence in the vulnerability of forests to drought. Nature, 491, 752-755.

Copolovici L, Kännaste A, Remmel T, Niinemets Ü (2014). Volatile organic compound emissions from Alnus glutinosa under interacting drought and herbivory stresses. Environmental \& Experimental Botany, 100, 55-63.

Dicke M, Loreto F (2010). Induced plant volatiles: From genes to climate change. Trends in Plant Science, 15, 115-117.

Dudareva N, Klempien A, Muhlemann JK, Kaplan I (2013). Biosynthesis, function and metabolic engineering of plant volatile organic compounds. New Phytologist, 198, 16-32.

Gao Y, Jin YJ, Li HD, Chen HJ (2005). Volatile organic compounds and their roles in bacteriostasis in five conifer species. Journal of Integrative Plant Biology, 47, 499-507.

Hartikainen K, Nerg AM, Kivimäenpää M, Kontunen-Soppela S, Mäenpää M, Oksanen E, Rousi M, Holopainen T (2009). Emissions of volatile organic compounds and leaf structural characteristics of European aspen (Populus tremula) grown under elevated ozone and temperature. Tree Physiology, 29, 1163-1173.

Hartmann H, Ziegler W, Trumbore S (2013). Lethal drought leads to reduction in nonstructural carbohydrates in Norway spruce tree roots but not in the canopy. Functional Ecology, 27, 413-427.

Hassan MN, Zainal Z, Ismail I (2015). Green leaf volatiles: biosynthesis, Biological functions and their applications in biotechnology. Plant Biotechnology Journal, 13, 727-739.

Hasunuma T, Takeno S, Hayashi S, Sendai M, Bamba T, Yoshimura S, Tomizawa K, Fukusaki E, Miyake C (2008). Overexpression of 1-Deoxy-D-xylulose-5-phosphate reductoisomerase gene in chloroplast contributes to increment of isoprenoid production. Journal of Bioscience and Bioengineering, 105, 518-526.

Hatanaka A (1993). The biogeneration of green odour by green leaves. Phytochemistry, 34, 1201-1218.

Hijioka Y, Lin E, Pereira J, Corlett R, Cui X, Insarov G, Lasco R, Lindgren E, Surjan A (2014). Asia. In: Christopher B, Vicente R eds. Climate Change 2014: Impacts, Adaptation, and Vulnerability, Part B: Regional Aspects, Contribution of Working Group II, Fifth Assessment Report of 
the Intergovernmental Panel on Climate Change. Cambridge University Press, Cambridge, UK. 1327-1370.

Hoch G, Richter A, Körner C (2003). Non-structural carbon compounds in temperate forest trees. Plant, Cell \& Environment, 26, 1067-1081.

Joó É, Dewulf J, Amelynck C, Schoon N, Pokorska O, Šimpraga M, Steppe K, Aubinet M, van Langenhove H (2011). Constitutive versus heat and biotic stress induced BVOC emissions in Pseudotsuga menziesii. Atmospheric Environment, 45, 3655-3662.

Jud W, Vanzo E, Li Z, Ghirardo A, Zimmer I, Sharkey TD, Hansel1 A, Schnitzler JP (2016). Effects of heat and drought stress on post-illumination bursts of volatile organic compounds in isoprene-emitting and non-emitting poplar. Plant, Cell \& Environment, 39, 1204-1215.

Klein T, Hoch G, Dan Y, Körner C (2014). Drought stress, growth and nonstructural carbohydrate dynamics of pine trees in a semi-arid forest. Tree Physiology, 34, 981-992.

Li L, Sheen J (2016). Dynamic and diverse sugar signaling. Current Opinion in Plant Biology, 33, 116-125.

Li P, Sun YF, Wang SG, Wang XD, Cai X, Zhu WZ, Paolo C, Li MH (2008). Altitudinal changes in leaf mass per unit area and tissue non-structural carbohydrates content of Abies fabri on Gongga Mountain of southwest China. Chinese Journal of Applied Ecology, 19, 8-12. [李蟠, 孙 玉芳, 王三根, 王小丹, 蔡小虎, 朱万泽, Cherybini Paolo, 李迈和 (2008). 贡嘎山地区不同海拔冷杉比叶 质量和非结构性碳水化合物含量变化. 应用生态学报, 19, 8-12.]

Lin SK, Lin J, Liu QL, Ai YF, Ke YQ, Chen C, Zhang ZY, $\mathrm{He} H$ (2014). Time-course of photosynthesis and nonstructural carbon compounds in the leaves of tea plants (Camellia sinensis, L.) in response to deficit irrigation. Agricultural Water Management, 144, 98-106.

Liu F, Zuo ZJ, Xu GP, Wu XB, Zheng J, Gao RF, Zhang RM, Gao Y (2013). Physiological responses to drought stress and the emission of induced volatile organic compounds in Rosmarinus officinalis. Chinese Journal of Plant Ecology, 37, 454-463. [刘芳, 左照江, 许改平, 吴兴波, 郑洁, 高 荣孚, 张汝民, 高岩 (2013). 迷迭香对干旱胁迫的生理 响应及其诱导挥发性有机化合物的释放. 植物生态学 报, 37, 454-463.]

Loreto F, Schnitzler JP (2010). Abiotic stresses and induced BVOCs. Trends in Plant Science, 15, 154-166.

Ma C, Feng YL, Zhang J, Wang HZ, Yuan JL, Li YJ (2017). Effects of exogenous methyl jasmonate on endogenous hormones and yield formation in wheat after anthesis under drought stress. Plant Physiology Journal, 53, 10511058. [马超, 冯雅岗, 张均, 王贺正, 原佳乐, 李友军 (2017). 外源茉莉酸甲酯对干旱胁迫下小麦花后内源激 素含量及产量形成的影响. 植物生理学报, 53, 10511058.]
Maguire AJ, Kobe RK (2015). Drought and shade deplete non-structural carbohydrate reserves in seedlings of five temperate tree species. Ecology and Evolution, 5, 57115721.

Marias DE, Meinzer FC, Woodruff DR, McCulloh KA (2017). Thermotolerance and heat stress responses of Douglas-fir and ponderosa pine seedling populations from contrasting climates. Tree Physiology, 37, 301-315.

McDowell N, Pockman WT, Allen CD, Breshears DD, Cobb N, Kolb T, Plaut J, Sperry J, West A, Williams DG, Yepez EA (2008). Mechanisms of plant survival and mortality during drought: Why do some plants survive while others succumb to drought? New Phytologist, 178, 719-739.

Morshedloo MR, Craker LE, Salami A, Nazeri V, Sang H, Maggi F (2017). Effect of prolonged water stress on essential oil content, compositions and gene expression patterns of mono- and sesquiterpene synthesis in two oregano (Origanum vulgare L.) subspecies. Plant Physiology \& Biochemistry, 111, 119-128.

Moses T, Pollier J, Thevelein JM, Goossens A (2013). Bioengineering of plant (tri) terpenoids: From metabolic engineering of plants to synthetic biology in vivo and in vitro. New Phytologist, 200, 27-43.

$\mathrm{Mu} \mathrm{ZZ}$ (2015). Research on the Impacts of High Temperature and Drought on Korla Fragrant Pear Photosynthetic Characteristics. Master degree dissertation, Xinjiang Agricultural University, Ürümqi. [穆蓁蓁 (2015). 高温干旱 对库尔勒香梨光合特性的影响研究. 新疆农业大学, 乌 鲁木齐.]

Murcia G, Pontin M, Reinoso H, Baraldi R, Bertazza G, Gómez-Talquenca S, Bottini R, Piccoli PN (2015). ABA and $\mathrm{GA}_{3}$ increase carbon allocation in different organs of grapevine plants by inducing accumulation of nonstructural carbohydrates in leaves, enhancement of phloem area and expression of sugar transporters. Physiologia Plantarum, 156, 323-337.

Nahar K, Hasanuzzaman M, Alam MM, Fujita M (2015). Exogenous glutathione confers high temperature stress tolerance in mung bean (Vigna radiate L.) by modulating antioxidant defense and methylglyoxal detoxification system. Environmental \& Experimental Botany, 112, 44-54.

Pan QM, Han XG, Bai YF, Yang JC (2002). Advances in physiology and ecology studies on stored non-structure carbohydrates in plants. Chinese Bulletin of Botany, 19, 30-38. [潘庆民, 韩兴国, 白永飞, 杨景成 (2002). 植物 非结构性諚藏碳水化合物的生理生态学研究进展. 植 物学报, 19, 30-38.]

Peñuelas J, Staudt M (2010). BVOCs and global change. Trends in Plant Science, 15, 133-144.

Ramak P, Osaloo SK, Ebrahimzadeh H, Sharifi M, Behmanesh $M$ (2013). Inhibition of the mevalonate pathway enhances carvacrol biosynthesis and DXR gene expression in shoot

www.plant-ecology.com 
cultures of Satureja khuzistanica Jamzad. Journal of Plant Physiology, 170, 1187-1193.

Santino A, Bonsegna S, Domenico SD, Poltronieri P (2010). Plant oxylipins and their contribution to plant defense. Current Topics in Plant Biology, 11, 103-111.

Silva EN, Ferreirasilva SL, Fontenele ADV, Ribeiro RV, Viégas RA, Silveira JAG (2010). Photosynthetic changes and protective mechanisms against oxidative damage subjected to isolated and combined drought and heat stresses in Jatropha curcas plants. Journal of Plant Physiology, 167, 1157-1164.

Staudt M, Morin X, Chuine I (2017). Contrasting direct and indirect effects of warming and drought on isoprenoid emissions from Mediterranean oaks. Regional Environmental Change, 17, 2121-2133.

Toroser D, Huber SC (1998). 3-Hydroxy-3-methylglutaryl-coenzyme A reductase kinase and sucrose-phosphate synthase kinase activities in cauliflower florets: $\mathrm{Ca}^{2+}$ dependence and substrate specificities. Archives Biochemistry \& Biophysics, 355, 291-300.

Trifilò P, Casolo V, Raimondo F, Petrussa E, Boscutti F, Gullo MAL, Nardini A(2017). Effects of prolonged drought on stem non-structural carbohydrates content and post-drought hydraulic recovery in Laurus nobilis L.: The possible link between carbon starvation and hydraulic failure. Plant Physiology and Biochemistry, 120, 232-241.

Velikova V, Varkonyi Z, Szabo M, Maslenkova L, Nogues I, Kovacs L, Peeva V, Busheva M, Garab G, Sharkey TD, Loreto F (2011). Increased thermostability of thylakoid membranes in isoprene-emitting leaves probed with three biophysical techniques. Plant Physiology, 157, 905-916.

Vickers CE, Possell M, Cojocariu CI, Velikova VB, Laothawornkitkul J, Ryan A, Mullineaux PM, Nicholas Hewitt C (2009). Isoprene synthesis protects transgenic tobacco plants from oxidative stress. Plant, Cell \& Environment, 32, 520-531.

Vitale M, Salvatori E, Loreto F, Fares S, Manes F (2008). Physiological responses of Quercus ilex leaves to water stress and acute ozone exposure under controlled conditions. Water, Air \& Soil Pollution, 189, 113-125.

Zhang T, Cao Y, Chen Y, Liu G (2015). Non-structural carbohydrate dynamics in Robinia pseudoacacia, saplings under three levels of continuous drought stress. Trees, 29, 1837-1849.

Zhao C, Wang HY, Liu MZ (2017). Metabolic regulation of soluble sugar, starch and related enzymes in cassava stems under drought stress. Plant Physiology Journal, 53, 795-806. [赵超, 王海燕, 刘美珍, 王文泉 (2017). 干旱 胁迫下木薯茎杆可溶性糖、淀粉及相关酶的代谢规律. 植物生理学报, 53, 795-806.]

Zhou S, Lin FP, Wang YK, Shen YB, Zhang RM, Gao RF, Gao $Y$ (2012). Effects of mechanical damage of leaves on volatile organic compounds and chlorophyll fluorescence parameters in seedlings of Cinnamomum camphora. Chinese Journal of Plant Ecology, 36, 671-680. [周帅, 林富平, 王玉魁, 沈应柏, 张汝民, 高荣孚, 高岩 (2012). 樟树 幼苗机械损伤叶片对挥发性有机化合物及叶绿素苂光 参数的影响. 植物生态学报, 36, 671-680.]

责任编委：李凤民 责任编辑：李 敏 